\title{
Title: LAMP Assays for the Simple and Rapid Detection of Clinically Important Urinary Pathogens Including the Detection of Resistance to 3rd Generation Cephalosporins
}

\author{
Lalainasoa Odile RIVOARILALA ( $\nabla$ odile.rivoarilala@gmail.com ) \\ Institut Pasteur de Madagascar \\ Victor JEANNODA \\ University of Antananarivo \\ Tania CRUCITTI \\ Institut Pasteur de Madagascar \\ Jean Marc COLLARD \\ Institut Pasteur of Shanghai/Chinese Academy of Sciences
}

\section{Research Article}

Keywords: loop-mediated isothermal amplification (LAMP), urinary tract infection, rapid diagnosis, CTX$\mathrm{M}$, resistance gene

Posted Date: April 29th, 2021

DOI: https://doi.org/10.21203/rs.3.rs-464488/v1

License: (c) (1) This work is licensed under a Creative Commons Attribution 4.0 International License.

Read Full License 


\section{Abstract}

Background: Timely and accurate identification of uropathogens and determination of their antimicrobial susceptibility is paramount to the management of urinary tract infections (UTIs). The main objective of this study was to develop an assay using LAMP (Loop mediated isothermal amplification) technology for simple, rapid and sensitive detection of the most common bacteria responsible for UTIs, as well as for the detection of the most prevalent genes (encoding cefotaximases from CTX-M group 1) responsible for resistance to 3rd generation of cephalosporins.

Method: We designed primers targeting Proteus mirabilis, while those targeting Escherichia coli, Klebsiella pneumoniae and Enterococcus faecalis and the CTX-M group 1 resistance gene were benchmarked from previous studies. The amplification reaction was carried out in a warm water bath for $60 \mathrm{~min}$ at $63 \pm 0.5$ ${ }^{\circ} \mathrm{C}$. The amplicons were revealed by staining with Sybr Green I. Specificity and sensitivity were determined using reference DNA extracts spiked in sterile urine samples. The analytical performance of the assays was evaluated directly on pellets of urine samples from patients suspected of UTI and compared with culture.

Results: We found a high specificity $(100 \%)$ for LAMP assays targeting the selected bacteria (P. mirabilis, E. coli, K. pneumoniae, E. faecalis) and the CTX-M group 1 when using DNA extracts spiked in urine samples. The sensitivities of the assays were around $1.510^{3}$ Colony Forming Units (CFU) / $\mathrm{mL}$ corresponding to the cut-off value used to define bacteriuria or UTIs in patients with symptoms. Out of 161 urine samples tested, using culture as gold standard, we found a sensitivity of the LAMP techniques ranging from 96 to $100 \%$ and specificity from 95 to $100 \%$.

Conclusion: We showed that the LAMP assays were simple and fast. The tests showed high sensitivity and specificity using a simple procedure for DNA extraction. In addition, the assays could be performed without the need of an expensive device such as a thermal cycler. These LAMP assays could be useful as an alternative or a complementary tool to culture reducing the time to diagnosis and guiding for more effective treatment of UTIs but also as a powerful diagnostic tool in resource-limited countries where culture is not available in primary health care structures.

\section{Introduction}

Urinary tract infections (UTIs) are among the most prevalent bacterial infections. They are a frequent reason for medical consultation and antimicrobial prescription in general medicine, ranking second after respiratory infections $[1,2]$. UTIs are mainly caused by Enterobacteriaceae, with a predominance of Escherichia coli, responsible for about $90 \%$ of the community acquired UTI and up to $65 \%$ of the UTI acquired in hospitals [3, 4]. During the period of 2002 to 2008, the bacterial UTIs in Madagascar were predominantly caused by $E$. coli with prevalence rates varying from $57-70 \%$, followed by other enterobacteria such as Klebsiella pneumoniae 9-11\% [5, 6], Enterobacter cloacae 7\% [5], and Proteus mirabilis 3\% [6]. Enterococcus faecalis, one of the most frequent Gram positive bacterium in UTI next to 
Staphylococcus saprophyticus and Streptococcus agalactiae, was ranking with a prevalence of $4 \%$ [5]. On the other hand, the spread of bacteria expressing extended spectrum $\beta$-lactamases (ESBL) in both hospital and community settings becomes a worldwide problem. The CTX-M types (cefotaximases) confer resistance to 3 rd generation cephalosporins (C3G) (i.e. cefotaxime, ceftriaxone, ceftazidime) and is the most widespread ESBL in the world [7-10]. During the period 2011-2013, Rasamiravaka et al. found $33 \%$ (77/234) of Gram-negative bacteria isolated from urine samples to be resistant to C3G in Antananarivo, Madagascar [11]. In 2016, the same prevalence rate of $33 \%(7 / 21)$ was found in urines, collected over a period of 4 months, of pregnant women with UTI attending the antenatal care clinic in the Hospital Center at Ambohimiandra, Antananarivo, Madagascar [12]. From January 2014 to October 2016, Rakotovao-Ravahatra et al., reported a prevalence of 22.5\% $(\mathrm{N}=23)$ E. coli producing ESBLs among a total of 102 E. coli responsible for UTI diagnosed at the University Hospital Center Befelatanana, Antananarivo, Madagascar [13]. Among the C3G resistance genes, those from the CTX-M group 1 are the most common worldwide [9]. In 2007, a study carried out in hospitals and community care sites in Madagascar, revealed the presence of plasmids dominated by bla-CTX-M15 encoding for beta-lactam resistance (CTX-M group 1) in Enterobacteriaceae isolates [14]. Traditionally, the diagnosis of UTI is performed using dipstick tests, microscopic urinalysis, and culture-based pathogen detection. Urine dipsticks are easy to use, but false negative results are often obtained in the case of non-nitrite-producing pathogens, large amount of vitamin C, or diluted urine samples [16]. Microscopic urinalysis is a labor intensive and less sensitive method in particular for samples with bacteria concentrations below $10^{5}$ Colony Forming Units (CFU)/mL [17]. Urine culture, which is the gold standard for bacteria detection and identification, requires skilled laboratory technicians and has a long turnaround time from sample collection to result covering steps of isolation and identification of the microorganisms (usually between $18-48 \mathrm{~h}$ ) followed by the determination of their susceptibility to antimicrobials (24h). Among the new diagnostic methods, flow cytometry, matrix assisted laser desorption ionization-time of flight mass spectrometry (MALDI-TOF MS) and molecular diagnostics-based assays have recently been established to accelerate the identification of bacteria directly from urine samples. The flow cytometry-based urine analyzer, UF-5000 (Sysmex), has been reported to be a useful screening tool of Gram-negative bacteria in urine samples (sensitivity and specificity of $91.7 \%$ and $90.0 \%$, respectively) but is limited to monobacterial infected urines containing $\geq 10^{5} \mathrm{CFU} / \mathrm{mL}$, thus its utility depends highly on the patient population [18]. MALDI-TOF MS has been evaluated for its ability to identify pathogens directly in urine samples; however this requires a complex and time-consuming procedure like centrifugation and washing [19]. These two latter methods need a high investment cost and are therefore not appropriate in the context of low- and middle-income countries. Loop mediated isothermal amplification (LAMP), is a molecular method established in 2000 [20], and recognized by its characteristics of being simple, rapid and highly reliable. In addition, it is a very cost-effective diagnostic method. Consequently, it has increasingly been applied for the detection of disease/pathogens and genes of interest [21,22]. Recently, we developed a highly performant LAMP-based assay for the simple and rapid detection of the four most common CTX-M groups, namely CTX-M groups 1, 2, 8 and 9 [23]. In the present study, we report on the evaluation of a new LAMP P. mirabilis assay together with three previously described LAMP assays targeting E. coli, K. pneumoniae, E. faecalis in their effectiveness to the detect UTIs. In addition, we 
investigated the performance of the LAMP CTX-M group 1 assay detecting the most prevalent group of cefotaximases found in Madagascar.

\section{Methods}

\section{Bacterial strains}

The reference and clinical isolates are summarized in Table 1. Reference strains were provided by the National Reference Center (NRC) for antibiotic resistance, Paris, France. The clinical isolates of other species present in UTI were obtained from the Clinical Biology Center (CBC), Pasteur Institute of Madagascar.

\section{Dna Extracts}

The strains were cultured using appropriate culture media and growth conditions. Two to three single colonies were suspended in $200 \mu \mathrm{L}$ of distilled water (DW), placed into a boiling water bath for $10 \mathrm{~min}$, subsequently transferred on ice for $5 \mathrm{~min}$ and then centrifuged at $20000 \mathrm{~g}$ for $5 \mathrm{~min}$. The supernatant was used as template in the LAMP reactions.

\section{Urine Samples}

\section{Spiked urine samples}

Two to three colonies obtained by culture of the reference strains, including E. coli, K. pneumoniae, P. mirabilis, E. faecalis and E. coli producing a bla-CTX-M15 cefotaximase were suspended in bacteria free urine and, then incubated at $37^{\circ} \mathrm{C}$ for 18 to $24 \mathrm{H}$. Subsequently, urine suspensions of $0.5 \mathrm{MacFarland}$ $(\mathrm{McF})$ turbidity $\left(\mathbb{1} 1.510^{8} \mathrm{CFU} / \mathrm{mL}\right.$ ) were used and $100 \mu \mathrm{L}$ of the suspensions were centrifuged at $20000 \mathrm{~g}$ for $5 \mathrm{~min}$. The supernatant was removed and the pellets were re-suspended in $10 \mu \mathrm{L}$ of DW. The sensitivities of the LAMP assays were determined by testing a range of 10 -fold dilutions of the suspensions.

\section{Urine samples from outpatients}

A total of 166 human urine samples were obtained from the CBC between August 2016 and January 2017. A volume of $100 \mu \mathrm{L}$ of each urine sample was centrifuged at $20000 \mathrm{~g}$ for $5 \mathrm{~min}$ and pellets were resuspended in $10 \mu \mathrm{L}$ of DW. Five microliters $(5 \mu \mathrm{L})$ of this suspension were used as template for LAMP assays. For each urine, the microbiological analysis was available.

\section{Lamp Assays}




\section{LAMP Primers}

LAMP primers for $P$. mirabilis were designed by using the online Primer Explorer V4 software [27] and according to the general criteria described by Notomi et al. (2000). The P. mirabilis target, wal $R$, encodes an enzyme of the glycosyl transferase family involved in the biosynthesis of lipopolysaccharides [28]. The walR sequences were obtained from GenBank NCBI (www.ncbi.nlm.nih.gov/) and were tested in silico through BLAST searches. Alignment analysis of available analogue nucleotide sequences (Accession number ADK56074.1, HM146786.1, HM146785.1, HQ25931.1, HQ25930.1, KQ960958.1) were performed to design the following P. mirabilis-specific primers: F3 (forward outer primer), B3 (backward outer primer), FIP (forward inner primer), BIP (backward inner primer) and LF (loop forward primer). The specificity of the designed primers was confirmed by BLAST on the NCBI server. The primer sequences for the LAMP assays are shown in Table 2. The LAMP primers for E. coli [24], K. pneumoniae [25] and $E$. faecalis [26] were selected from the literature. LAMP primers for CTX-M group 1 detection were used as described previously [23].

\section{LAMP reaction}

The LAMP reaction was performed as described previously [23]. Briefly, $5 \mu \mathrm{L}$ of DNA extract or sample was used as template in the reaction. Distilled water (DW) was used as negative control. The reaction was carried out in an Eppendorf $\circledast$ tube and incubated at $63 \pm 2^{\circ} \mathrm{C}$ in a thermo block for 60 min and was then heated at $80 \pm 5^{\circ} \mathrm{C}$ for $5 \mathrm{~min}$ to stop the reaction. The LAMP products were detected by direct visual inspection after addition of one microliter $(1 \mu \mathrm{L})$ of Sybr Green I (SG I) $10000 \mathrm{X}$ (http://www.sigmaaldrich.com) in the post reaction volume. A positive reaction was indicated by a change of color from orange to yellow, while a negative reaction had no change of color.

\section{Analytical performance of the LAMP assays}

The specificity of LAMP assays targeting P. mirabilis, E. coli, K. pneumoniae and E. faecalis were performed using DNA extracts obtained from 16 different bacterial species reference strains belonging to genera frequently isolated from UTI and 20 other anaerobic and facultative anaerobic strains isolated from UTI cases and particularly with 38 P. mirabilis clinical isolates for LAMP P. mirabilis (Table 1). Products were examined visually by staining with SG I and after electrophoresis on a $1.5 \%$ agarose gel 120 Volts $-45 \mathrm{~min}$. The assays were performed in triplicate to ensure its repeatability. The sensitivity of the five LAMP assays (E. coli, K. pneumoniae, P. mirabilis, E. faecalis and CTX-M group 1) was assessed in quintuplicate on a 10 - fold serial dilution of spiked urine samples ranging from $10^{1}$ to $10^{7} \mathrm{UFC} / \mathrm{mL}$. Products were examined visually by staining with SG I and analyzed by electrophoresis on a $1.5 \%$ agarose gel -120 Volts $-45 \mathrm{~min}$. The sensitivity was defined as the lowest concentration detected by the assay in four out of the five experiments.

\section{Clinical performance of the five LAMP assays}

One hundred microliter of the patient's urine samples were centrifuged at $20000 \mathrm{~g}$ for $5 \mathrm{~min}$. The pellets were suspended with $10 \mu \mathrm{L}$ of DW. Five microliters of the suspension were used as template in each 


\section{Statistical Methods}

The diagnostic performance of the LAMP assays was reported as sensitivity, specificity, negative predictive value (NPV), positive predictive value (PPV) with 95\% confidence interval (Cl), considering culture as the gold standard. The agreement between diagnostic tests was calculated using Cohen's kappa coefficient. Calculations were performed using Medcalc Easy software.

\section{Ethics}

Ethical approval was not requested for this study because all clinical samples used were archived coded remnant samples provided by the $\mathrm{CBC}$ after all diagnostic assays in the context of the laboratory diagnosis of UTI were performed. The study was anonymously performed.

\section{Results}

\section{Analytical performance of the LAMP assays}

The BLAST analysis of the designed primers amplifying the walR gene from $P$. mirabilis did not show any mismatches. In addition, the P. mirabilis LAMP assay amplified only the DNA of the reference U2A 1878 and all 38 clinical strains of $P$. mirabilis (Table 1). No cross amplification was observed with the non- $P$. mirabilis reference $(N=16)$ strains (Fig. 1) nor with other clinical isolates causing UTIs $(N=20)$. The specificity of the LAMP assays targeting E. coli, K. pneumoniae and E. faecalis was further confirmed by successful amplification of only the corresponding reference strains (data not shown). Positive SYBR Green I LAMP products or expected bands on agarose gels were only observed in the presence of the target DNA from reference strains. All triplicate results were concordant. The sensitivity for each assay was determined around $1.510^{3} \mathrm{UFC} / \mathrm{mL}$ (Fig. 2).

\section{Clinical performance of LAMP assays}

Out of the 166 urines collected and tested, five samples were excluded due to a polymicrobial population or a contaminated urine without a second sample analysis. The LAMP method was compared to bacterial culture, the gold standard, for 161 samples. The results are presented in Table 3. Using LAMP assays, E. coli, K. pneumoniae, P. mirabilis, and E. faecalis were detected in 15.5\% (25/161), 8.7\% (14/161), $1.9 \%$ (3/161), $2.0 \%$ (4/161) of the samples, respectively, while culture identified $E$. coli in $14.9 \%$ (24/161), K. pneumoniae in 3.7\% (6/161), P. mirabilis in 1.9\% (3/161) and E. faecalis in $1.2 \%(2 / 161)$ of the urine samples. Both techniques detected equally $P$. mirabilis (3/161) and the CTX-M group 1 genes $(11 / 161)$ (Table 3). Note that all CTX-M group 1-LAMP positives were found resistant to C3G by culture and belonged to enterobacteria species such as E. coli (4/11), K. pneumoniae (3/11), P. mirabilis (1/11), Enterobacterspp. (1/11) and other Gram-negative bacteria such as Acinetobacter ursinguii (1/11) and 
Citrobacter freundii (1/11). The overall, sensitivity and specificity of LAMP assays ranged from 96-100\% (Cl: 15-100\%) and from 95-100\% (Cl: 95-100\%), respectively. The agreement between the LAMP assays and culture was the highest for $P$. mirabilis $(\mathrm{K}=1)$ and the CTX-M group1 assays $(\mathrm{K}=1)$, almost perfect for $E$. coli $(\mathrm{K}=0,93)$, moderate for the $K$. pneumoniae $(\mathrm{K}=0.58)$ and $E$. faecalis $(\mathrm{K}=0.66)$ assays (Table 3).

\section{Discussion}

We developed and evaluated several LAMP assays for the simple and rapid detection of clinically important uropathogens (i.e. E. coli, K. pneumoniae, E. faecalis, P. mirabilis) and genes encoding the most widespread cefotaximases (CTX-M group 1, including CTX-15 the most widespread cefotaximase detected in Madagascar).

The overall sensitivity of the LAMP assays was around $1.510^{3} \mathrm{CFU} / \mathrm{mL}$ which corresponds to the threshold of bacteriuria $\left(10^{3} \mathrm{CFU} / \mathrm{mL}\right.$ for bacteria such as $E$. coli, enterobacteria other than $E$. coli and Enterococcus) associated with a leucocyturia $>10^{4} / \mathrm{mL}$ in symptomatic patients [1]. This sensitivity was 10 to 100 time higher than that of the study of Etchebarne BE et al. (2017) which was $1.1010^{5} \mathrm{CFU} / \mathrm{mL}$ for LAMP targeting E. coli, $5010^{3} \mathrm{CFU} / \mathrm{mL}$ for K. pneumoniae, $15010^{3} \mathrm{CFU} / \mathrm{mL}$ for E. faecalis and $2010^{3}$ $\mathrm{CFU} / \mathrm{mL}$ for $P$. mirabilis [29]. However, Etchebarne BE et al., performed a DNA extraction by heating.

In our study, we have demonstrated that a LAMP assay applied to urine samples without an extraction step is possible. The five LAMP assays we tested herein were all found specific. The side-by-side performance of LAMP and culture was based on the test of 161 urine samples. The LAMP assays were able to detect all K. pneumoniae, E. faecalis, P. mirabilis and CTX-M group 1 resistance genes, but missed one $E$. coli in one infected urine. The LAMP assays detected additionally two E. coli, eight K. pneumoniae and two $E$. faecalis infected urines, which may be explained by the higher analytical sensitivity of the LAMP assays compared to culture results.. From practical point of view, this LAMP method is simple and rapid. It did not require a complex DNA extraction step. LAMP assays provided a significantly shorter turnaround time compared to culture (1h30 vs 3 days).

Comparing to other studies, the specificity values of our LAMP assays to detect $E$. coli (99\%), $K$. pneumoniae (95\%) and E. faecalis (99\%) were close to those found by Rödel et al. (2017), 97\% ( $n=157)$ for $E$. coli, $99 \%(n=157)$ for K. pneumoniae and $98 \%(n=71)$ for $E$. faecalis. It is worthwhile to mention that the latter assays were performed in blood culture and the amplification were carried out using the eazyplex ${ }^{\circledR}$ commercial test and Genie II machine [30]. Additionally, Etchebarne et al. (2017) found similar results for overall specificities (97\%), using the culture as a reference method [29]. When compared to culture of urine, we obtained eight false positive results with the $K$. pneumoniae-LAMP assay on urines which we could not investigate in this study. Similarly, Dong et al. (2012) detected seven false positive in 110 K. pneumoniae clinical sputum with PCR as reference method [31]. However, this team and others obtained the expected target sequences after sequencing the LAMP products [31-33] suggesting that the 
false positives were most probably true positives and thus adding evidence to the superior sensitivity of the LAMP assay $[34,35]$.

The potential benefit of the LAMP assays developed in this study is their ability to detect not only bacteria responsible for UTI but also the most common resistance to C3G antibiotics, the CTX-M group 1. The early diagnosis of this gene could lead to improving the antibiotic therapy and antimicrobial stewardship.

We did not include DNA extraction steps; simplifying considerably the procedure. LAMP assays have shown a significant tolerance to amplification inhibiting substances derived from a number of biological samples including urine [36-38]. Thereby, some LAMP assays with high sensitivity and simple procedure for DNA extraction have been developed for molecular detection of bacterial [39] and parasitic [40] infections in urine samples. Additionally, a simple DNA extraction method by heating has been successfully applied with other types of clinical samples, such as blood in the LAMP assay for Plasmodium [41] and cutaneous swabs for the detection of Leishmania species [42]. In the study of Gandasegui et al. (2015), among the three DNA extraction methods tested, the higher performance of the LAMP assay for $S$. haematobium detection in urine samples was obtained after heating the pellet obtained after centrifugation of the samples and using it as template for the LAMP reaction. The heating step was necessary to free, besides $S$. haematobium DNA, DNA from the parasite eggs [43]. Based on the previous studies, we performed a centrifugation and a heat treatment as a simple pre-treatment of samples. In addition, the LAMP reaction was performed in a water bath and did not require a thermal cycler. The amplification products were detected visually by observing a color change without the need of any other equipment. Finally, the turnaround time of analysis including preparation of the sample, the LAMP assay and the interpretation of the products was around $90 \mathrm{~min}$. All these characteristics advocate the use of this method as a simple, inexpensive and performant assay adapted to the settings encountered in low- and middle-income countries. However, this study has some limitations. In order to diagnose, treat and manage UTIs, besides the presence of bacteria in a concentration $>10^{3} \mathrm{CFU} / \mathrm{mL}$, the leucocyturia, the aspects of the urine and symptoms of the patient has to be taken into account. Besides, other pathogens such as Enterobacter spp., Citrobacter spp and Staphylococcus spp. could be responsible for UTI and those are not yet covered in our current assays. In our perspective, the UTI-LAMP assays were developed as alternative tools for health facilities in low-income countries where culture cannot be implemented. However, if culture is done in routine it should not be disregarded and the LAMP assays could be implemented as a complement to culture with the aim to accelerate the detection of resistant pathogens. Additionally, a quantitative approach could be used, performing real-time turbidity measurements of the LAMP reaction and extrapolating the time to result with the $\mathrm{CFU} / \mathrm{mL}$ of the target pathogen [31][44].

\section{Conclusion}

The LAMP method may be used as an alternative or complementary tool to culture for early detection of common uropathogens and resistance genes from the CTX-M group 1 adapted to resource-limited settings. 


\section{Abbreviations}

UTIs : urinary tract infections ; LAMP: Loop mediated isothermal amplification ; CTX-M : cefotaximases ; C3G : 3rd generation cephalosporins ; CFU : Colony Forming Units ; MALDI-TOF MS : matrix assisted laser desorption ionization-time of flight mass spectrometry ; $\mathrm{CBC}$ : Clinical Biology Center Clinical ; DW : Distilled water ; SG I : Sybr Green I; NPV : negative predictive value ; PPV : positive predictive value ; $\mathrm{Cl}$ : confidence interval.

\section{Declarations}

\section{Acknowledgments}

The authors thank Pr Patrice Courvalin, Antimicrobien Agents Unit, National Reference Center (NRC), Pasteur Institute of Paris for the kind provision of reference strains used for the specificity assays and Dr Frederique Randrianirina, Clinical Center of Biology, Pasteur Institute of Madagascar, Antananarivo, Madagascar, for the kind provision of the clinical isolates and specimens used for the evaluation test in this study. We specially thank all staff of Bacteriology Experimental Unit, Pasteur Institute of Madagascar, Antananarivo Madagascar.

\section{Authors' contributions}

RLO carried out all experiments in laboratory, data analysis, wrote the first draft of the manuscript. JMC designed and supervised the work. TC, JMC and VJ contributed to the final version of the manuscript. All authors read and approved the final manuscript.

\section{Funding}

This work was funded by Dedonder Clayton (EC/MAN/N³05/12), Pasteur Institute of Paris.

\section{Availability of data and materials}

The datasets used and/or analysed during the current study are available from the corresponding author on reasonable request.

\section{Ethics approval and consent to participate}

Not applicable.

\section{Consent for publication}

Not applicable.

\section{Competing interests}

The authors declare that they have no competing interests. 


\section{References}

1. SPLIF. Diagnostic et antibiothérapie des infections urinaires bactériennes communautaires de l'adulte. 2015.

2. Akram M, Shahid M KA. Etiology and antibiotic resistance patterns of community-acquired urinary tract infections in J N M C Hospital Aligarh, India. Ann Clin Microbiol Antimicrob. 2007;6:4.

3. Kucheria R, Dasgupta P, Sacks S KM\& SN. Urinary tract infections: new insights into a common problem. Postgrad Med J. 2005;81(952):83-6.

4. LM. W. Antibiotic resistance changing management of urinary tract infections in aged care. Med $\mathrm{J}$ Aust. 2015;203(9):352.

5. Ramilitiana B, Rakotoarivelo R, Razafimahefa S, Vololontiana D, Randrianarison A, Randria M, et al. Prévalence de la résistance des bactéries aux antibiotiques dans les infections urinaires de l'adulte en milieu hospitalier à Antananarivo. Médecine d'Afrique Noire. 2014;61(10).

6. Randrianirina F, Soares J, Carod J, Ratsima E, Thonnier V, Combe P, et al. Antimicrobial resistance among uropathogens that cause community-acquired urinary tract infections in Antananarivo, Madagascar. J Antimicrob Chemother. 2007;59:309-12.

7. Cantón R, Coque T. The CTX-M beta-lactamase pandemic. Curr Opin Microbiol. 2006;9:466-75.

8. D’Andrea M. M., Arena F., Pallecchi L. RGM. CTX-M-type $\beta$-lactamases:a successful story of antibiotic resistance. J Med Microbiol. 2013;303(6-7):305-17.

9. Bevan ER, Jones AM, Hawkey PM. Global epidemiology of CTX-M $\beta$-lactamases: temporal and geographical shifts in genotype. J antimicrob Chemother. 2017;1-11.

10. Lee MY, Ko K, CI K, D C, Peck KR, Song J. High prevalence of CTX-M-15-producing Klebsiella pneumoniae isolates in Asian countries: diverse clones and clonal dissemination. Int J Antimicrob Agents. 2011;38:160-3.

11. Rasamiravaka T, Shaista Sheila HSL, Rakotomavojaona T, Rakoto-Alson AO RT. Changing profile and increasing antimicrobial resistance of uropathogenic bacteria in Madagascar. Infect Médecine Mal. 2015;45:173-6.

12. Rasamiravaka, T, Batavisoa, E, Ranaivosoa M\& R. A. Profile and antimicrobial resistance to newly available drugs of urinary tract pathogens among Malagasy pregnant women. Trop Biomed. 2016;33(1):1-6.

13. Rakotovao-Ravahatra ZD, Randriatsarafara FM, Rasoanandrasana S, Raverohanta L R AL. Phénotypes de résistance des souches d'Escherichia coli responsables d'infection urinaire au laboratoire du Centre Hospitalo-Universitaire de Befelatanana Antananarivo. Pan Afr Med J. 2017;26:166.

14. Rakotonirina HC, Garin B, Randrianirina F, Richard V, Talarmin A, Arlet G. Molecular characterization of multidrug-resistant Enterobacteriaceae isolated in Antananarivo, Madagascar. BMC Microbiol. 2013;13(85):1-10. 
15. Talan D, Takhar S, Krishnadasan A, Abrahamian F, Mower W, Moran G et al. FluoroquinoloneResistant and Extended-Spectrum $\beta$ - Lactamase Producing Escherichia coli Infections in Patients with Pyelonephritis, United States. Emerg Infect Dis. 2016;22, №9(9).

16. T. Demilie, G. Beyene, S. Melaku and W. Tsegaye, BMC Res Notes, 2014, 7 481-485. Diagnostic accuracy of rapid urine dipstick test to predict urinary tract infection among pregnant women in Felege Hiwot Referral Hospital, Bahir Dar, North West Ethiopia. BMC Res Notes. 2014;7:481-5.

17. Johnson JR. Laboratory diagnosis of urinary tract infections in adult patients [letter]. Clin Infect Dis. 2004;39:873-4.

18. Rita De Rosa, Shamanta Grosso, Giada Lorenzi, Graziano Bruschetta AC. Evaluation of the new Sysmex UF-5000 fluorescence flow cytometry analyser for ruling out bacterial urinary tract infection and for prediction of Gram negative bacteria in urine cultures. Clin Chim Acta. 2018;484:171-8.

19. M. Inigo, A. Coello, G. Fernandez-Rivas, B. Rivaya, J. Hidalgo MDQ and VA. Direct Identification of Urinary Tract Pathogens from Urine Samples, Combining Urine Screening Methods and MatrixAssisted Laser Desorption Ionization-Time of Flight Mass Spectrometry. J Clin Microbiol. 2016;54:988-93.

20. Notomi T, Okayama $\mathrm{H}$, Masubuchi $\mathrm{H}$, Yonekawa T, Watanabe $\mathrm{K}$, Amino $\mathrm{N}$ et al. Loop-mediated isothermal amplification of DNA. Nucleic Acids Res. 2000 Jun;28(12):E63.

21. Fu S, Qu G, Guo S, Ma L. Applications of Loop-Mediated Isothermal DNA Amplification. 2011;84550 .

22. Fu S, Qu G, Guo S, Ma L. Applications of Loop-Mediated Isothermal DNA Amplification. Appl Biochem Biotechnol. 2011;163:845-50.

23. Rivoarilala OL, Garin B, Andriamahery F CJ. Rapid in vitro detection of CTX-M groups 1, 2, 8, 9 resistance genes by LAMP assays. PLoS One. 2018;13(7):e0200421.

24. Hill J, Beriwal S, Chandra I, Paul VK, Kapil A, Singh T, et al. Loop-Mediated Isothermal Amplification Assay for Rapid Detection of Common Strains of Escherichia coli. J Clin Microbiol. 2008;46(8):2800-4.

25. Dong D, Liu W, Li H, Wang Y, Li X, Zou D, et al. Survey and rapid detection of Klebsiella pneumoniae in clinical samples targeting the rcsA gene in Beijing, China. Front Microbiol. 2015;6(MAY):1-6.

26. Kato H, Yoshida A, Ansai T, Watari H, Notomi T, Loop-mediated TT. Loop-mediated isothermal amplification method for the rapid detection of Enterococcus faecalis in infected root canals. Oral Microbiol Immunol. 2007;22:131-5.

27. Eiken Chemical Co. Ltd, Tokyo, Japan. Available from: http://primerexplorer.jp/elamp4.0.0/index.html

28. Aquilini E, Azevedo J, Jimenez N, Bouamama L, Toma JM, Regue M. Functional Identification of the Proteus mirabilis Core Lipopolysaccharide Biosynthesis Genes. J Bacteriol. 2010;192(17):4413-24.

29. Etchebarne BE, Li Z, Stedtfeld RD, Nicholas MC, Williams MR, Johnson TA, et al. Evaluation of Nucleic Acid Isothermal Amplification Methods for Human Clinical Microbial Infection Detection. Front Microbiol. 2017;8:2211. 
30. Rödel J, Bohnert J, Stoll S, Wassill L, Edel B, Karrasch M. Evaluation of loop-mediated isothermal amplification for the rapid identification of bacteria and resistance determinants in positive blood cultures. Eur J Clin Microbiol Infect Dis. 2017;36:1033-1040.

31. Kim DW, Kilgore PE, Kim EJ, Kim SA, Anh DD, Dong BQ, et al. The Enhanced Pneumococcal LAMP Assay: A Clinical Tool for the Diagnosis of Meningitis Due to Streptococcus pneumoniae. PLoSONE. 2012;7(8):1-8.

32. Lee D, Kim EJ, Kilgore PE, Kim SA, Takahashi H. Clinical Evaluation of a Loop-Mediated Isothermal Amplification (LAMP) Assay for Rapid Detection of Neisseria meningitidis in Cerebrospinal Fluid. PLoSONE [Internet]. 2015;(April). Available from: http://dx.doi.org/10.1371/journal.pone.0122922

33. Mckenna JP, Kim DW. A Novel Loop-Mediated Isothermal Amplification Assay for Serogroup Identification of Neisseria meningitidis in Cerebrospinal Fluid. Front Microbiol. 2016;6(January):1-8.

34. Pillai D, Bonami JR, Sri Widada J. Rapid detection of Macrobrachium rosenbergiinodavirus (MrNV) and extra small virus (XSV), the pathogenic agents of white tail disease of Macrobrachium rosenbergii (De Man), by loop-mediated isothermal amplification. J Fish Dis. 2006;29:275-283.

35. Teng PH, Chen PF, Lee FC, Ou BR, Lee PY. Specific detection of reverse transcription-loop-mediated isothermal amplification amplicons for Taura syndrome virus by colorimetric dot-blot hybridization. $\mathrm{J}$ Virol Methods. 2007;146:317-26.

36. Kaneko Hisatoshi, Takashi Kawana, Fukushima Eiko, Suzutani Tatsuo. Tolerance of loop-mediated isothermal amplification to a culture medium and biological substances. J Biochem Biophys Methods. 2007;70(3):499-501.

37. Patrice F, Manuela T, Jonathan H, Eve-Julie B, Catharina C, Tsugunori $\mathrm{N}$ et al. Robustness of a loopmediated isothermal amplication reaction for diagnostic applications. FEMS Immunol Med Microbiol. 2011;62:41-8.

38. Hidenori Tani, Tatsuya Teramura, Ken Adachi, Satoshi Tsuneda, Shinya Kurata, Kazunori Nakamura, Takahiro Kanagawa NN. Technique for Quantitative Detection of Specific DNA Sequences Using Alternately Binding Quenching Probe Competitive Assay Combined with Loop-Mediated Isothermal Amplification. Anal Chem. 2007;79(15):5608-5613.

39. Koizumi N, Nakajima C, Harunari T, Tanikawa T, Tokiwa T, Uchimura E, et al. A New Loop-Mediated Isothermal Amplification Method for Rapid, Simple, and Sensitive Detection of Leptospira spp. in Urine. J Clin Microbiol. 2012;50(6):2072-4.

40. Reyes J, Solon J, Rivera W. Development of a loop-mediated isothermal amplification assay for detection of Trichomonas vaginalis. Diagn Microbiol Infect Dis. 2014;79:337-41.

41. Polley SD, González IJ, Mohamed D, Daly R, Bowers K, Watson J et al. Clinical evaluation of a loop mediated amplification kit for diagnosis of imported malaria. J Infect Dis. 2013;208(4):637-44.

42. Mikita K, Maeda T, Yoshikawa S, Ono T, Miyahira Y KA. The Direct Boil-LAMP method: a simple and rapid diagnostic method for cutaneous leishmaniasis. Parasito Intest. 2014;63:785-789.

43. Gandasegui J, Fernández-soto P, Carranza-rodríguez C. The Rapid-Heat LAMPellet Method: A Potential Diagnostic Method for Human Urogenital Schistosomiasis. PLoS Negl Trop Dis. 
2015;9(7):e0003963.

44. Mori Y, Kitao M, Tomita N, Notomi T. Real-time turbidimetry of LAMP reaction for quantifying template DNA. J Biochem Biophys Methods. 2004;59(2):145-57.

\section{Tables}

Due to technical limitations, table 1 to 3 is only available as a download in the Supplemental Files section.

\section{Figures}

A
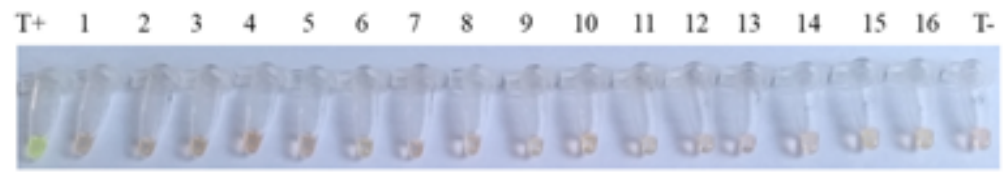

B

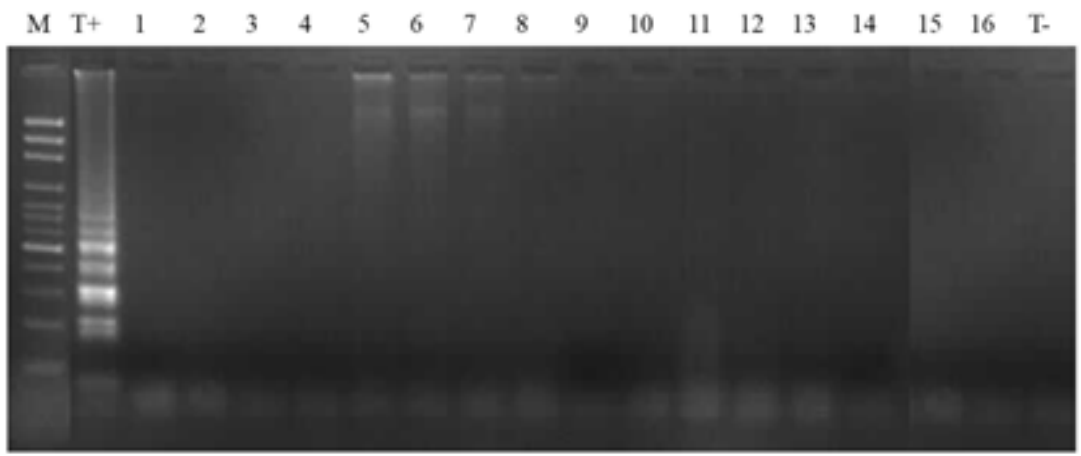

\section{Figure 1}

The BLAST analysis of the designed primers amplifying the walR gene from P. mirabilis did not show any mismatches. In addition, the P. mirabilis LAMP assay amplified only the DNA of the reference U2A 1878 and all 38 clinical strains of P. mirabilis (Table 1). No cross amplification was observed with the non-P. mirabilis reference $(\mathrm{N}=16)$ strains nor with other clinical isolates causing UTIs $(\mathrm{N}=20)$. 
A

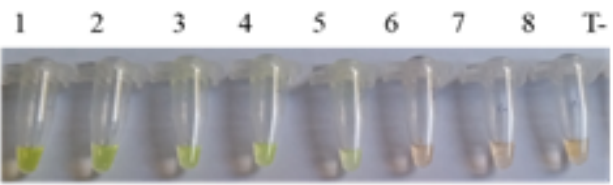

B

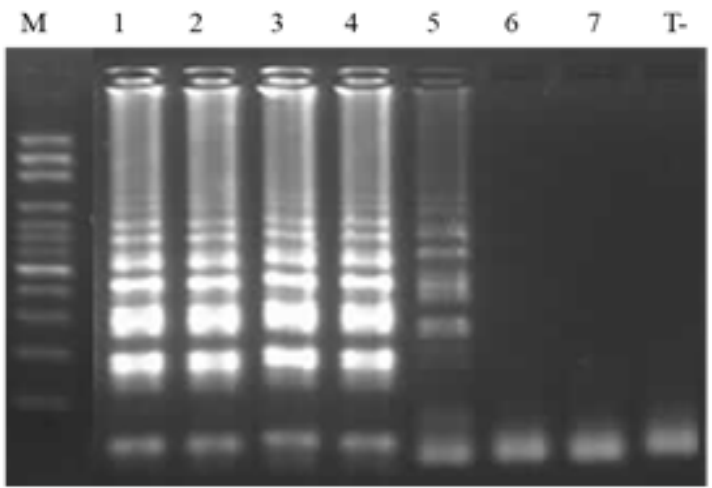

\section{Figure 2}

The specificity of the LAMP assays targeting E. coli, K. pneumoniae and E. faecalis was further confirmed by successful amplification of only the corresponding reference strains (data not shown). Positive SYBR Green I LAMP products or expected bands on agarose gels were only observed in the presence of the target DNA from reference strains. All triplicate results were concordant. The sensitivity for each assay was determined around $1.5103 \mathrm{UFC} / \mathrm{mL}$

\section{Supplementary Files}

This is a list of supplementary files associated with this preprint. Click to download.

- Table1.xlsx

- Table2.xlsx

- Table3.xlsx 